\title{
MORFOLOGÍA DE NEOCHETINA EICHHORNIAE (WARNER) (COLEOPTERA: CURCULIONIDAE)
}

\author{
Oscar MARTÍNEZ-MORALES, EDITH G. ESTRADA-VENEGAS, ARMANDo \\ EQUIHUA-MARTÍNEZ \& JORGE VALDEZ-CARRASCO \\ Colegio de Postgraduados, Fitosanidad, Programa de Entomología y Acarología. Km 36.5 carretera \\ México-Texcoco, Montecillo Texcoco Edo. de México. C.P. 56230. \\ Edith Estrada, <edith_ev@yahoo.com.mx>
}

Martínez-Morales, O., Estrada-Venegas, E. G., Equihua-Martínez, A. \& Valdez-Carrasco, J. 2014. Morfología de Neochetina eichhorniae Warner (Coleoptera: Curculionidae). Acta Zoológica Mexicana (n. s.), 30(2): 247-267.

RESUMEN. En este trabajo se describen e ilustran características morfológicas de Neochetina eichhorniae (Warner, 1970). Esta especie se ha utilizado para el control biológico del lirio acuático (Eichhornia crassipes (Mart.) Solms-Laubach, 1883). En el huevo, el aspecto cambiante del corion es dado por el desarrollo embrionario. En la larva se realizó una descripción de la quetotaxia de la cápsula cefálica y se identificaron tres ínstares larvales con la medición de su anchura; también se revisó la microescultura del cuerpo de la larva, sobresaliendo unas microespinas, cuyo arreglo es diferente en tórax y abdomen, también se observaron dos tipos de espiráculos; el más característico es el espiráculo abdominal por su posición dorsal, que además de ser esclerosado, posee órganos sensoriales en su ápice. La morfología externa de los adultos de $N$. eichorniae es muy parecida en ambos sexos; su principal diferencia se encuentra en el rostrum. Además se proporciona una descripción de las alas, proventrículo y genitalia, estructuras importantes en la taxonomía. Las características morfológicas de $N$. eichhorniae encontradas en éste trabajo pueden ser útiles para diferenciar a esta especie de Neochetina bruchi (Hustache, 1926), la cual ha sido liberada en muchos países. Es el primer trabajo de morfología N. eichhorniae en México. Palabras clave: genitalia, estados inmaduros, lirio acuático, morfología, Neochetina eichhorniae.

Martínez-Morales, O., Estrada-Venegas, E. G., Equihua-Martínez, A. \& Valdez-Carrasco, J. 2014. Morphology of Neochetina eichhorniae Warner (Coleoptera: Curculionidae). Acta Zoológica Mexicana (n. s.), 30(2): 247-267.

ABSTRACT. In this study morphological characteristics of Neochetina eichhorniae (Warner, 1970) are described and illustrated. This species has been used for the Biological Control of waterhyacinth (Eichhornia crassipes (Mart.) Solms-Laubach, 1883). In the egg, the changing appearance of the chorion is given by the embryonic development. Description of larval head capsule chaetotaxy was done. Three larval instars were identified by measuring the head capsule width; microsculpture of the body larva was studied, microspines were evident with different arrangements in thorax and abdomen, two types of spiracles were found; the more distinctive was the dorsal spiracle in the abdomen, which is sclerotized, with

Recibido: 06/06/2011; aceptado: 06/06/2014. 
sensory organs at its apex. The external morphology of $N$. eichorniae adult is very similar in both sexes, the main difference among them is the rostrum. Description of the wings, proventriculus and genitalia, important structures in the taxonomy, is provided. The morphological characteristics of N. eichhorniae found in this study can be use to separate from $N$. bruchi (Hustache) which has been released in many countries. This is the first morphological study of $N$. eichhorniae in Mexico.

Keywords: Genitalia, immature stages, water hyacinth, morphology, Neochetina eichhorniae.

\section{INTRODUCCIÓN}

El género Neochetina (Coleoptera: Curculionidae: Erirhininae: Bagoini), está conformado por 6 especies originarias de la parte sur y central del continente americano; todas son semiacuáticas y se alimentan de plantas de la familia Pontederiaceae. Estas especies presentan un amplio rango de variación en los caracteres taxonómicos utilizados para diferenciarlas (Warner 1970; O’Brien 1976; Center et al. 1988). La identificación de las especies es muy difícil en los estados de huevo, larva y pupa (Center et al. 2002). La ubicación taxonómica específica es esencial y puede ser la diferencia entre un éxito o fracaso en un programa de control biológico (González-Hernández \& López-Arrollo 2007). En México se encuentran presentes solo dos especies Neochetina eichhorniae Warner posiblemente introducido en los 70's (Bennet 1984 \& O’Brien 1976) y Neochetina bruchi Hustache introducido en 1994, de material libre de patógenos proveniente de Florida ( Martínez et al. 2001). El presente trabajo, primero que se efectúa en México, teniendo como objetivo describir aspectos de la morfología externa del huevo, larva y adulto de Neochetina eichhorniae Warner, especie que se utiliza en el control biológico de lirio acuático, e ilustrar las estructuras morfológicas en que se basa la taxonomía, como una contribución al conocimiento integral de la especie.

\section{MATERIALES Y MÉTODO}

Se obtuvo una colonia del pie de cría de $N$. eichhorniae que se encuentra en las instalaciones del Colegio de Postgraduados Campus Montecillo, cuyos organismos fueron colectados en el Lago de Chapala. El material se examinó con énfasis en las principales características morfológicas de la especie. Las observaciones de huevo (10 huevos) se hicieron in vivo, colocándolos en una gota de agua destilada sobre el portaobjetos. Para su medición se utilizaron huevos conservados en alcohol al 70\% (20 huevos). Para la obtención de las imágenes de las 30 cápsulas cefálicas que se iban a medir, las larvas se orientaron sobre alcohol en gel transparente. Las larvas utilizadas en microscopía de barrido, se obtuvieron de material fijado en alcohol al $70 \%$, se deshidrataron en alcoholes al 80,90 y $100 \%$ y se secaron en una secadora de punto crítico Samdri 780A. Las muestras se montaron en portaobjetos metálicos de $1 \mathrm{~cm}$ de diámetro, con cinta conductora de cobre y se cubrieron con una capa de oro de $70 \mathrm{~nm}$ en una ionizadora de oro JEOL Fine Coat JFC-1100. Las fotografías se 
realizaron en la unidad de microscopía electrónica del Colegio de Postgraduados, con un microscopio electrónico de barrido modelo JEOL JSM-6390/LGS.

Para el estudio morfológico y registro fotográfico de algunas estructuras de los adultos como cabeza, tórax, abdomen, élitros y patas, las muestras se prepararon en seco. En el caso de las alas se realizaron preparaciones semipermanentes con glicerina (Domínguez 2006).

También se hicieron montajes en bálsamo de Canadá para estudiar la genitalia de hembras y machos. Para ésto, se maceraron 20 abdómenes completos en hidróxido de potasio al $10 \%$ a $80{ }^{\circ} \mathrm{C}$ durante 20 minutos, y se lavaron en agua con $1 \%$ de ácido acético antes de extraer y montar las estructuras, previa deshidratación en alcoholes y aclarado en xilol (Gaiger \& Vanin 2008; Castañeda et al. 2007). En las preparaciones se elevó el cubreobjetos con dos bandas de papel Bond de $20 \mathrm{~mm}$ de largo y 1 de ancho.

Las imágenes y escalas se obtuvieron con un Fotomicroscopio Tessovar y un Fotomicroscopio III, ambos de Carl Zeiss, con una cámara digital para microscopía PaxCam 5. Las medidas se hicieron con el analizador de imágenes Image tool for Windows versión 3.0 (Wilcox et al. 2002). El analizador se calibró con imágenes de un micrómetro de objeto Carl Zeiss. El procesamiento de las imágenes se hizo con el programa GIMP 2.6.1. El material se tiene en la colección Entomológica del Colegio de Postgraduados.

\section{RESULTADOS Y DISCUSIÓN}

Huevo. El huevo de Neochetina eichhorniae mide $894 \pm 57 \mu \mathrm{m}$ de longitud ( $\mathrm{n}=30$ ) y $577 \pm 67 \mu \mathrm{m}$ en su parte más ancha $(\mathrm{n}=30)$. Es ligeramente más angosto en su polo anterior, en donde se distingue una pequeña protuberancia redondeada. El corion completamente liso y transparente, de consistencia suave, casi membranosa, permite ver el interior, de manera que el aspecto cambiante de textura y coloración que muestra obedece a los diversos grados del desarrollo embrionario. En el día 1, antes de desarrollarse el embrión, casi todo el contenido del huevo es granuloso excepto en sus bordes, donde el material es un poco más claro. En el espacio comprendido entre el corion y el cúmulo de material denso se puede observar una capa de vitelo formada por gránulos esféricos uniformes, que vistos al microscopio dan la apariencia de que la superficie del huevo es ornamentada. En lugares en donde el contenido del huevo hace inflexiones se puede ver la membrana vitelina, también hialina y lisa. La naturaleza flexible del corion permite que la totalidad del huevo cambie de forma para adaptarse a las nuevas distribuciones del vitelo y tejido embrionario que se mueven en el interior (Fig. 1). En lo referente al tamaño del huevo, es similar a lo reportado por Martínez (2005) $0.88 \mathrm{~mm}$, y superior a los $0.75 \mathrm{~mm}$ mencionados por Center et al. (1988; 2002), sin embargo, en el primero se trata de un manual que no indica si 

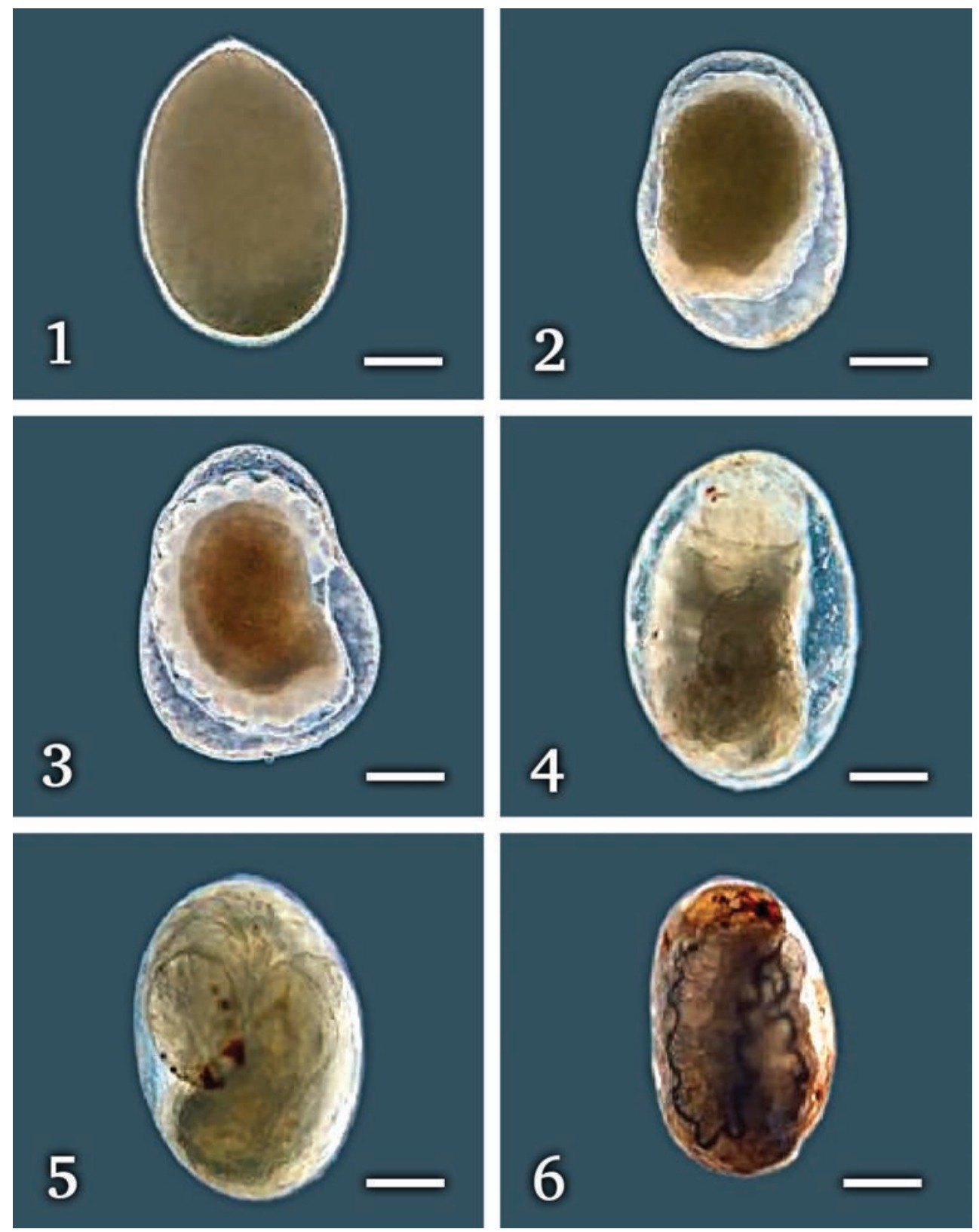

Figuras 1-6. (1) Huevo de Neochetina eichhorniae en su fase inicial. (2) Diferenciación del contenido del huevo, el embrión envuelve al vitelo. (3) Embrión envuelto en la parte ventral por amnios y serosa. (4-6) Larva ya formada; resaltan los ojos simples, las mandíbulas y los troncos traqueales. Escala: $200 \mu \mathrm{m}$. 
este dato es original, ni tampoco la fuente de dónde se obtuvo. La forma es igual a lo descrito por los autores antes citados, aunque ellos no describen el desarrollo del huevo.

Para el día 2, en las fases iniciales del desarrollo embrionario hay una diferenciación del contenido del huevo en un material denso al centro, que se separa del vitelo más claro en la periferia. De este material central se va a diferenciar posteriormente el embrión, el cual se distingue del resto del contenido porque muy pronto muestra las características constricciones que separan a cada uno de los segmentos embrionarios (Fig. 2). En el día 4, el embrión en desarrollo se encuentra en el exterior de este cúmulo, envolviendo a una gran masa central de vitelo. Toda la periferia del embrión está envuelta por la membrana embrionaria llamada serosa, mientras que la membrana amnios envuelve al embrión sólo ventralmente (Fig. 3). Cuando el embrión se cierra dorsalmente (día 6), la futura larva ya se puede observar como tal a través del corion (Fig. 4). A pesar de que el insecto en formación tiene en esta fase la misma coloración que el vitelo que aún conserva, al igual que las membranas embrionarias, es fácilmente discernible la cápsula cefálica ovalada donde se distinguen y pigmentan, antes que cualquier otra estructura, las mandíbulas y los ojos simples (Fig. 5). Después viene un esclerosamiento general de la cabeza y pronto se distinguen los dos troncos traqueales longitudinales que recorren todo el cuerpo de la larva (Fig. 6).

Larvas. Cápsula cefálica. La cápsula cefálica de la larva recién emergida del huevo comienza a esclerosarse, ya que aún es color sepia claro. El cuerpo, sin embargo, es casi transparente y a través de su cutícula se pueden observar algunos órganos internos, entre los que destacan los dos troncos traqueales longitudinales que van, a cada lado, desde el tórax hasta la cauda. La cabeza de la larva del primer ínstar tiene en promedio $351 \mu \mathrm{m}$ de anchura, larva extendida alcanza $3 \mathrm{~mm}$ de longitud. Después de la emergencia, el cuerpo de la larva 1 continúa translúcido, pero los órganos internos adquieren una apariencia blanquecina que se extiende al aspecto general de la larva, el cual se hace más denso en la larva del segundo ínstar y aún más en la del tercero. La larva 2 tiene una anchura promedio de cápsula cefálica de $470 \mu \mathrm{m}$ y un cuerpo extendido de $4 \mathrm{~mm}$. En la larva 3 la cabeza mide en promedio $727 \mu \mathrm{m}$ de ancho y el cuerpo $6 \mathrm{~mm}$ de longitud. El color de la cápsula cefálica varía del anaranjado (Center et al. 1998; 2002) al café rojizo descrito por May \& Sands (1986). Esta variación de color se da por el cambio de esclerosamiento, que aumenta con la edad de la larva. En este trabajo encontramos que en las medidas de las cápsulas cefálicas de los tres ínstares hay diferencias respecto a lo reportado en 1976 por Deloach \& Cordo; en el primer ínstar tenemos $50 \mu \mathrm{m}$ más, en el segundo ínstar $30 \mu \mathrm{m}$ menos y en el tercer ínstar $30 \mu \mathrm{m}$ más.

La cutícula de la cápsula cefálica es microesculturada, ornamentada por estrías rugosas y ramificadas que pueden formar segmentos libres o se pueden combinar para dibujar celdas cerradas, sobre todo en las áreas parietales. La sutura coronal 
se intersecta con las suturas frontales exactamente en el centro de la cabeza en su vista frontal. Los extremos inferiores de las líneas frontales terminan separados de las antenas, por afuera de éstas. En las áreas epicraneales, cerca del vértice central, destaca la seta dorsal epicraneal 1 (des1). Esta nomenclatura de las setas cefálicas se basa en los trabajos de Marvaldi (1997 y 2003), y en Gosik (2009). Hay además una hilera de 5 setas pequeñas alineadas longitudinalmente en la parte media de las placas epicraneales, que se ordenarán según su cercanía con el tramo medio de la línea ecdisial (des2-des6). Alineados también en la misma hilera, se encuentran dos poros (p) arriba de la des2, un poro por debajo de la des4 y otro entre la des1 y la des6 (Fig. 7). A los lados de la cápsula cefálica se encuentran las setas laterales epicraneales (les), enumeradas desde el borde posterior de la cabeza hacia adelante. La seta les1 está muy cerca del vértice inferoposterior de la placa epicraneal; la les2 está arriba casi a la altura de la des3, mientras que la les3 se ubica en la parte inferior de la placa, muy cerca de la línea ecdisial frontal (Figs. 7 y 8). En la placa frontal están las setas del mismo nombre (fs), enumeradas de arriba hacia abajo. Las fs1 están cerca del punto donde convergen las tres líneas ecdisiales. Las fs2 son las más grandes y se encuentran junto a las líneas ecdisiales frontales, casi a la mitad de su trayecto. Cerca del centro de la placa frontal se ubican las microsetas fs3 y debajo de ellas las macrosetas fs4. Las fs5 son muy pequeñas y se encuentran en la parte inferior lateral del área frontal (Fig. 7). En el clípeo, hay 4 microsetas alineadas horizontalmente cerca del borde superior y el labro tiene 4 setas grandes, un par superior y otro inferior (Figs. 7 y 8). Cabe mencionar que las tres setas dorsales epicraneales que se encuentran en la parte media de la cápsula cefálica presentan un tamaño similar al de las setas que se encuentran en la parte superior de la misma, por lo cual también se tomaron como setas des; sin embargo, en Marvaldi (1997 y 2003), y en Gosik (2009) estas setas no se nombran como tales, y solo aparecen como marcas en los dibujos.

Cuerpo de la larva. La suma de los tres segmentos torácicos de la larva ocupa apenas la sexta parte de la longitud total del cuerpo. Cada segmento está marcado por profundas constricciones intersegmentales que separan a lóbulos membranosos tergales, pleurales y esternales; entre ellos está un gran lóbulo tergal protorácico cubierto por una placa esclerosada, ovalada y de posición transversal, cuyos bordes se adelgazan para integrarse a la cutícula membranosa del tórax (Fig. 9). A los lados del mencionado lóbulo protorácico se encuentra el primer par de espiráculos del cuerpo sobre un esclerito redondeado de cutícula lisa con dos ranuras longitudinales y dos lóbulos atrás de ellas. La superficie anterior de los lóbulos torácicos dorsales, laterales y ventrales, con microesculturas y con hileras de microespinas dirigidas hacia atrás (Figs. 10 y 11). Los seis primeros segmentos abdominales de la larva tienen, cada uno, una mitad anterior notoriamente más abultada que la posterior. En cada uno de estos anillos mayores hay dos lóbulos pleurales bien definidos por un pliegue horizontal y uno vertical. La cutícula membranosa de los segmentos abdominales está surcada por es- 

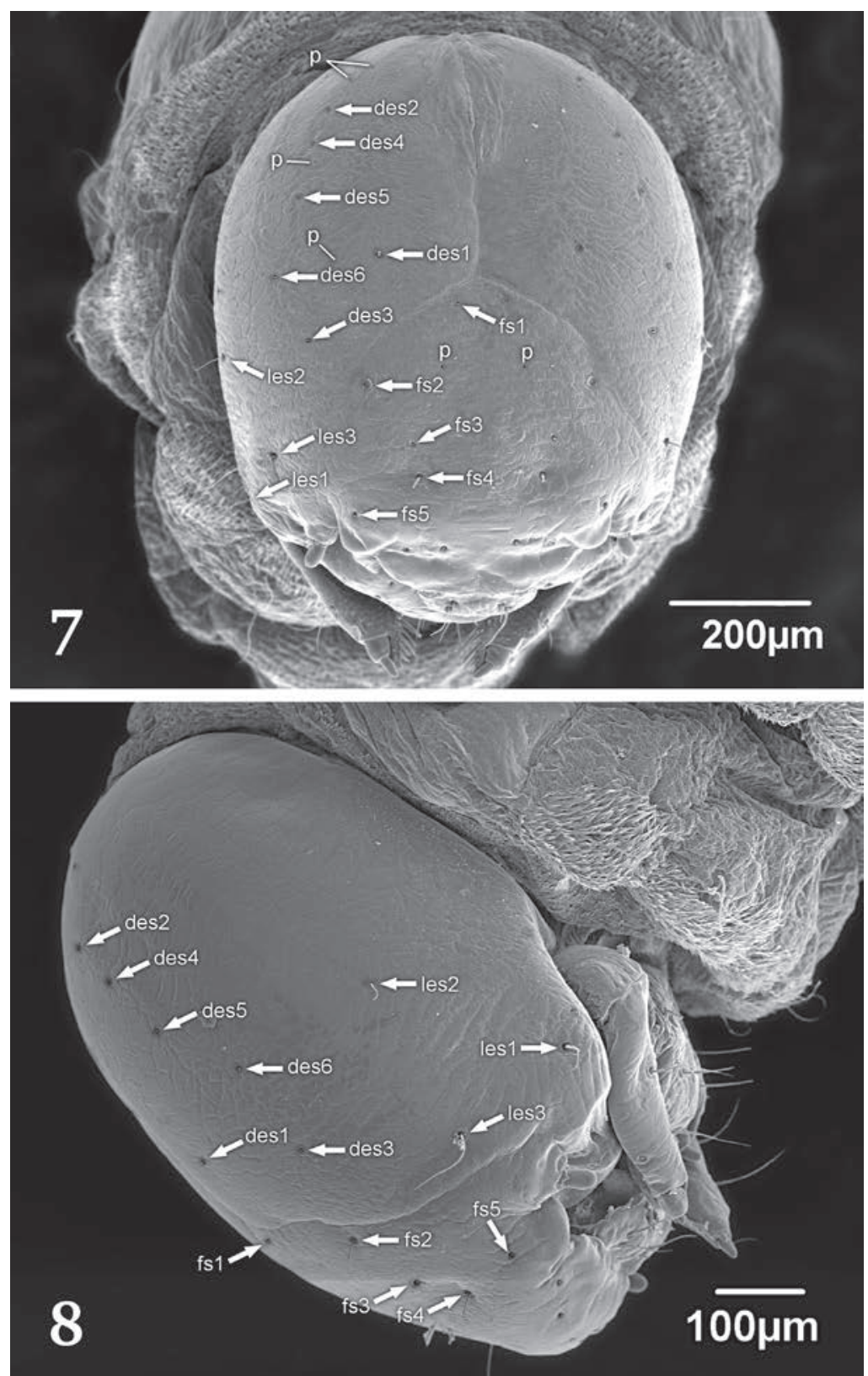

Figuras 7 y 8. Cabeza de larva del tercer ínstar de $N$. eichorniae. (7) Mapa de setas cefálicas, vista frontal. (8) Mapa de setas cefálicas, vista lateral. 

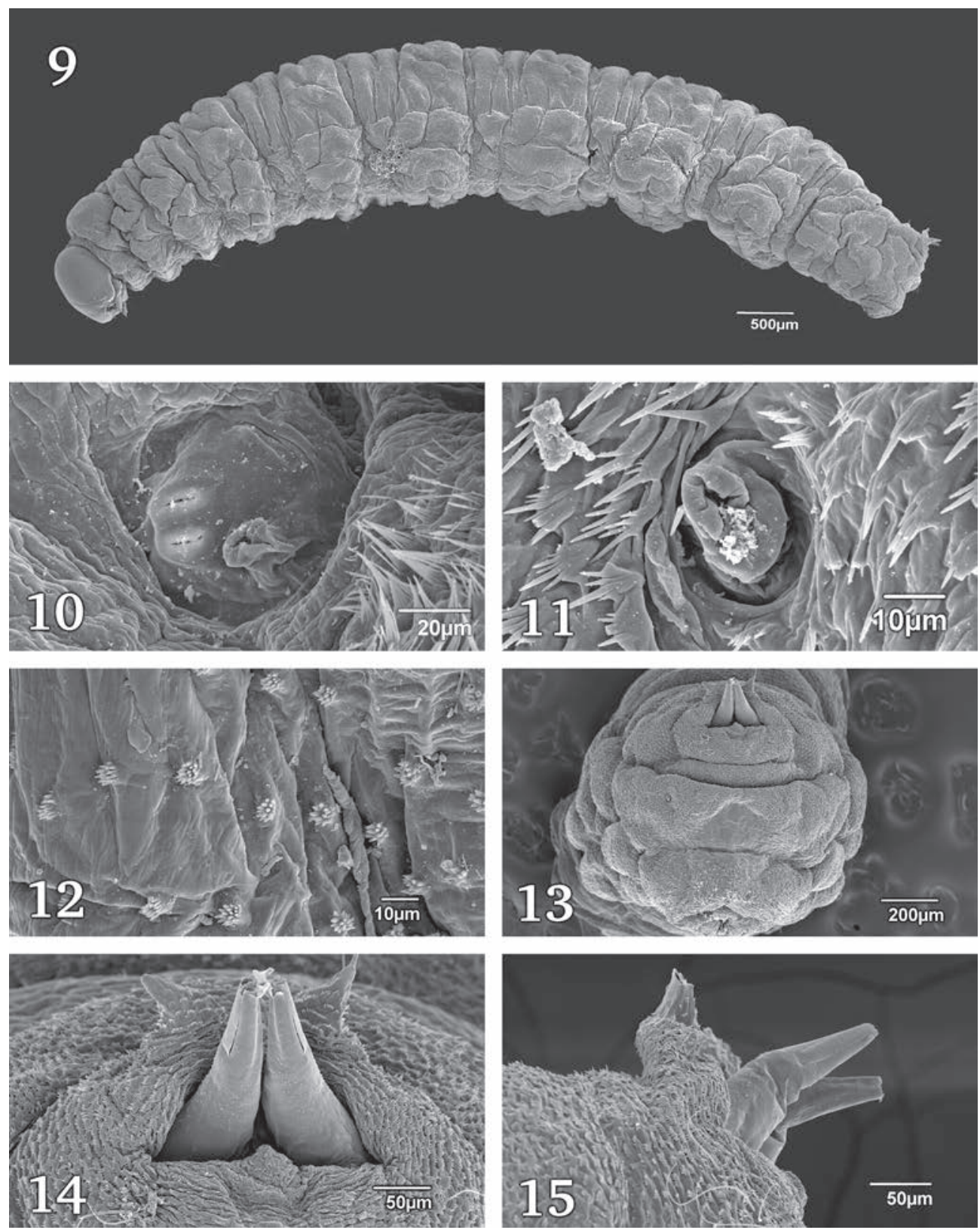

Figuras 9-15. (9) Cuerpo de la larva de tercer ínstar. (10) Espiráculo protorácico. (11) Espiráculo protorácico y ornamentaciones del cuerpo de la larva. (12) Agrupamiento de microespinas en el abdomen. (13) Parte posterior de la larva con espiráculos tubulares en la parte superior. (14) Espiráculos tubulares, vista posterior. (15) Espiráculos tubulares en vista lateral. 
trías predominantemente longitudinales, las cuales son más marcadas en el fondo de los pliegues intersegmentales. Las áreas laterales y ventrales del abdomen microesculturadas y con microespinas dirigidas hacia atrás, similares a las torácicas, pero el número de dientes es más reducido. En los lóbulos abdominales tergales las espinas están agrupadas sobre pequeños tubérculos redondos, separados unos de otros y equidistantes (Fig. 12). Los segmentos abdominales VII y VIII no tienen la diferenciación de diámetros que muestran los segmentos I-VI, ni lóbulos o pliegues que diferencien a los tergos, pleuras y esternones. En el extremo dorsal del último segmento hay una gran protuberancia que lleva a los dos espiráculos abdominales posteriores, los cuales forman tubos esclerosados cónicos abiertos en el extremo y con ranuras longitudinales. Arriba de los tubos espiraculares hay dos lóbulos puntiagudos que llevan en el extremo órganos sensoriales (Figs. 13, 14 y 15). Las ornamentaciones superficiales en el extremo posterior del abdomen son muy similares a las torácicas. Marvaldi (2003) presentó una clave basada en caracteres morfológicos externos de las larvas de las diferentes subfamilias de Curculionidae y en especial la subfamilia Erirhininae; menciona que la cabeza es relativamente pequeña en relación al cuerpo, generalmente con cóndilos postoccipitales sobresalientes, y espiráculos modificados para la vida acuática (se encuentran en posición dorsal). Estos últimos fueron tomados en cuenta por May \& Sands en 1986 para diferenciar a las larvas de Neochetina bruchi Hustache y N. eichhorniae Warner de otros miembros de la subfamilia Erirhininae, como son Neohydronomus pulchellus Hustache, Cyrtobagous singularis Hustache y C. salviniae Calder y Sands, utilizados para el control de malezas acuáticas en Australia. Julien et al. (1999), Center et al. (2002) y Martínez (2005) mencionan que la larva de $N$. eichhorniae es ápoda, con setas alargadas, y una cápsula cefálica amarilla, a diferencia de los colores anaranjado a café rojizo observados en este estudio.

Adultos. Cabeza. La cabeza en ambos sexos tiene una cápsula cefálica casi esférica, aunque las órbitas oculares sobresalen ligeramente del contorno de la cápsula, a diferencia de otros curculiónidos (Figs. 16 y 17). La cápsula cefálica es tan ancha como larga en vista dorsal sin considerar al rostrum, sólo que el tamaño de la cápsula es diferente entre la hembra (Fig. 20) y el macho (Fig. 21). La longitud del rostrum en la hembra, medida a lo largo de su curvatura es de $1.58 \mathrm{~mm}$, y en el macho es de 1.20 mm (Figs. 22 y 23). La anchura del rostrum no es uniforme; es mínima en la base (0.35 mm en la hembra; $0.25 \mathrm{~mm}$ en el macho), aunque en el macho, el punto más estrecho está más alejado de la cápsula cefálica. El punto de anchura máxima es también diferente en ambos sexos; en la hembra se encuentra en el extremo de la probóscide a la altura de las articulaciones mandibulares, mientras que en el macho se encuentra antes del extremo del rostrum, entre las articulaciones antenales y mandibulares. La distancia interocular en la hembra y macho es menor a medio milímetro (Figs. 20 y 21). En la hembra y el macho, el 50\% de la longitud total de las antenas corresponde al escapo (Figs. 20, 21, 24 y 25). La cutícula de la cápsula cefálica está 

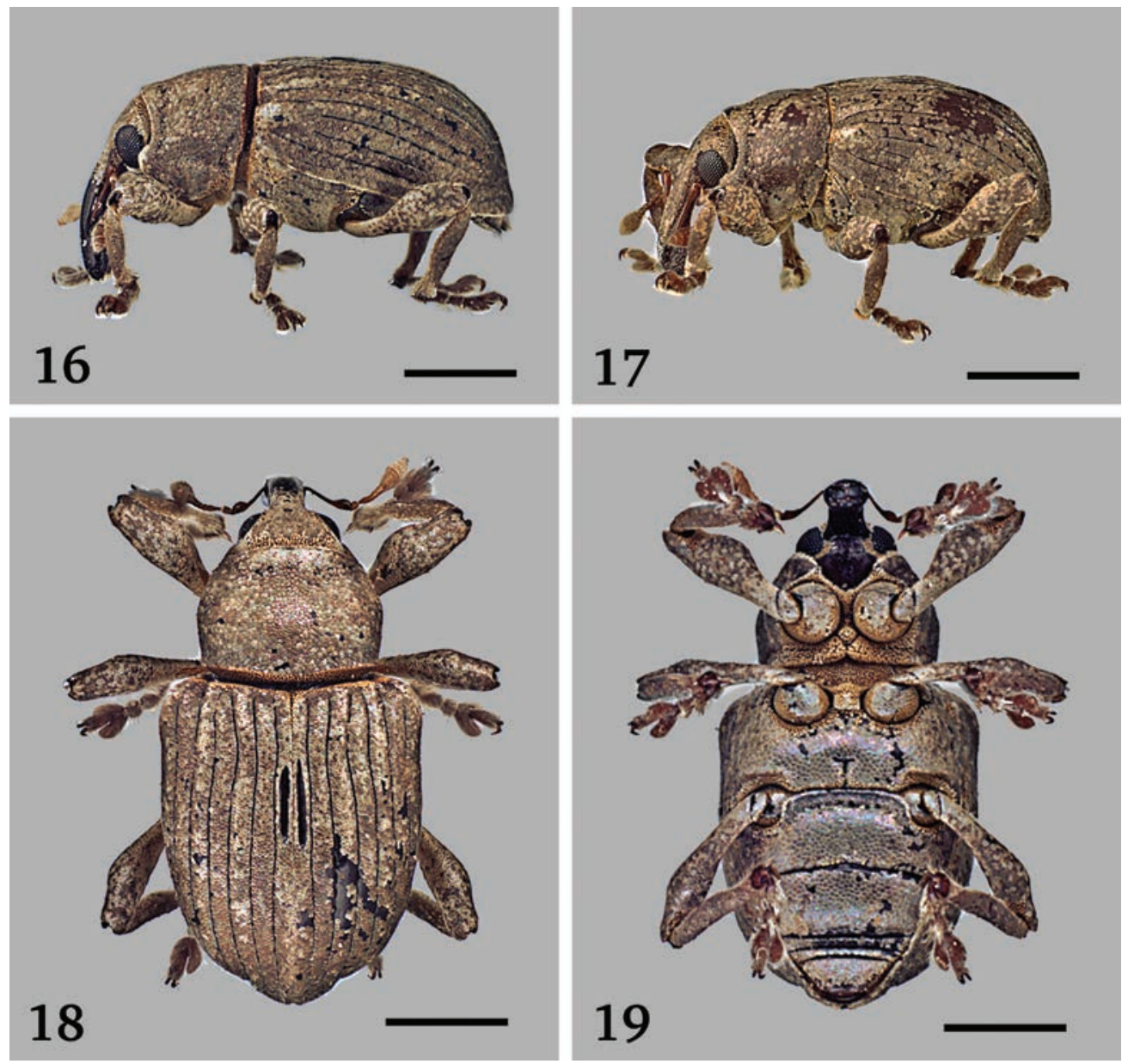

Figuras 16-19. Neochetina eichhorniae en estado adulto. (16) Vista lateral de la hembra. (17) Vista lateral del macho. (18) Hembra en vista dorsal (19) Hembra en vista ventral. Escala: 1 mm.

cubierta por una franja dorsal de escamas blancas desde el borde posterior de los ojos compuestos hasta el margen occipital. Estas escamas son más densas y de distribución más uniforme en la hembra que en el macho (Figs. 24 y 25). Las áreas laterales y ventrales, de los ojos hacia atrás, son de cutícula desnuda, sin escamas. La frente tiene una cubierta de escamas redondas mucho más grandes que las dorsales; esta cubierta se extiende hasta un poco antes de la mitad de la longitud del rostrum en la hembra, pero en el macho llegan más allá de las bases antenales (Figs. 20-23). El resto de la superficie del rostrum en la hembra es de cutícula desnuda, oscura y brillante con puntuaciones equidistantes, incluyendo a toda su área posterior (Fig. 24); en el 

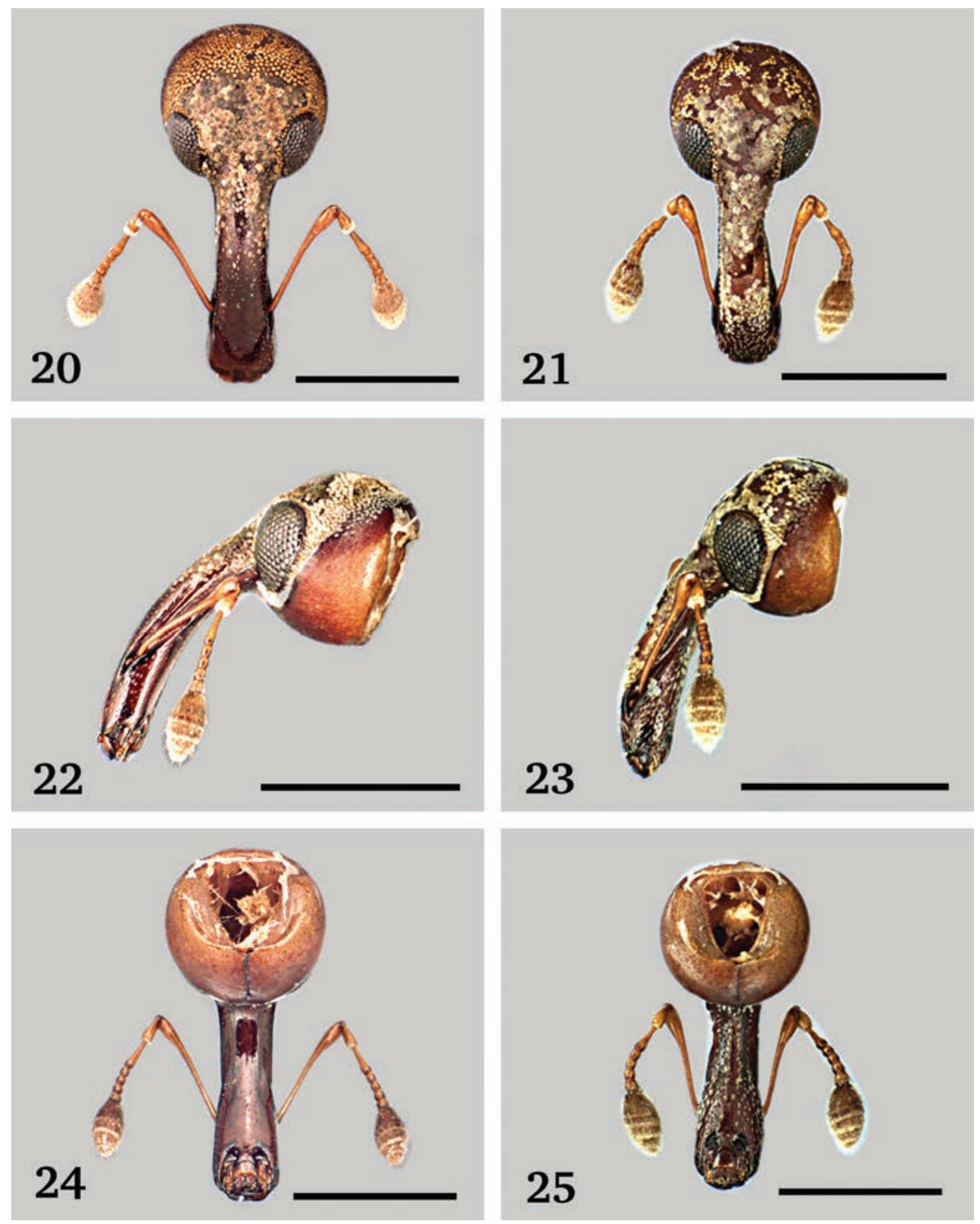

Figuras 20-25. Morfología de la cabeza de N. eichhorniae. (20 y 21) Vista anterior de la cabeza de hembra y macho. (22 y 23) vista lateral de la cabeza de hembra y macho. (24 y 25) Vista posterior de la cabeza de hembra y macho. Escala: $1 \mathrm{~mm}$. 
macho toda esta zona del rostrum tiene microsetas (Fig. 25). La longitud total de los adultos se midió en vista dorsal (Fig. 18), desde la parte basal del rostrum hasta la parte posterior de los élitros, y la anchura en la parte más ancha del tórax. La hembra mide $5.0 \mathrm{~mm}$ de longitud y $2.51 \mathrm{~mm}$ de ancho, mientras el macho mide $4.55 \mathrm{~mm}$ de longitud y $2.27 \mathrm{~mm}$ de ancho (Figs. 16-18); esto es similar a las dimensiones mencionadas por Oberholzer (2001), aunque el suyo no es un artículo formal, y difiere de lo reportado por Warner en 1970 en donde la hembra mide $3.3 \mathrm{~mm}$ de longitud y $1.8 \mathrm{~mm}$ de ancho. Center et al. (2002) mencionan que el macho y la hembra miden $2 \mathrm{~mm}$ y $3 \mathrm{~mm}$ de longitud, respectivamente; esto debido probablemente a que ellos midieron sólo el área de los élitros. Las medidas también son diferentes de lo encontrado por O’Brien en 1976 con un tamaño de 2-4.5 mm de longitud, y por Martínez en 2005 donde el tamaño máximo es de $4.5 \mathrm{~mm}$. En cuanto a la longitud del rostrum también hay diferencias de lo reportado por Warner en 1970 para ambos sexos, con una diferencia de 0.20 y $0.30 \mathrm{~mm}$.

Tórax. Protórax. En la vista dorsal, el protórax presenta contornos curvos, casi circulares, excepto en el borde posterior que es recto (Fig. 26). Visto lateralmente, se aprecia que el borde anterior del protórax es de diámetro notoriamente menor que el posterior. El margen anterior describe curvaturas laterales que se adaptan a los bordes posteriores de los ojos compuestos, ya que la cabeza se encuentra retraída hasta este punto dentro del protórax (Fig. 30). La zona ventral de este segmento está ocupada casi en su totalidad por las dos cavidades coxales circulares y cóncavas en cuyo fondo, desplazadas hacia los lados, están las fosas coxales (Fig. 27). Los bordes anterior y posterior del protórax, así como el área esternal alrededor de las coxas, están cubiertos por microescamas amarillas; el resto del segmento tiene escamas grandes de tonos variados entre el blanco y el marrón oscuro (Figs. 26, 27, 28 y 29). Las coxas anteriores son prácticamente esféricas, cubiertas por microescamas amarillas y escamas grandes sólo en su lado externo; alrededor del borde articular, la coxa es desnuda. El fémur de la patas protorácicas tiene una longitud de $1.5 \mathrm{~mm}$ y una parte media abultada de $0.6 \mathrm{~mm}$ de diámetro. La parte más angosta $(0.26 \mathrm{~mm})$ está en la base, junto al trocánter. En esta base angosta el fémur tiene una mancha bien delimitada de microescamas de color amarillo oscuro; el resto tiene una cubierta de escamas grandes. Las tibias anteriores alcanzan una longitud de $1.66 \mathrm{~mm}$, están cubiertas por escamas y en su extremo por setas claras y densas; el borde distal tiene un fleco de pilosidades uniformes y un espolón dirigido hacia atrás que termina con ápice agudo. Todo el tarso tiene una pubescencia densa y blanca y el penúltimo tarsómero con dos lóbulos ovalados. Las uñas son simples y de trayecto curvo paralelo, no divergentes.

De acuerdo con Marvaldi \& Lanteri (2005), el contorno del protórax y los élitros determinan la forma del cuerpo del organismo. El pronoto es más ancho que largo, con pocas excepciones (por ejemplo en Curculioninae, Erodiscini), y no está carinado a diferencia de algunos taxas superiores (Antibrinae, Belidae y Oxicorinae). Clark 

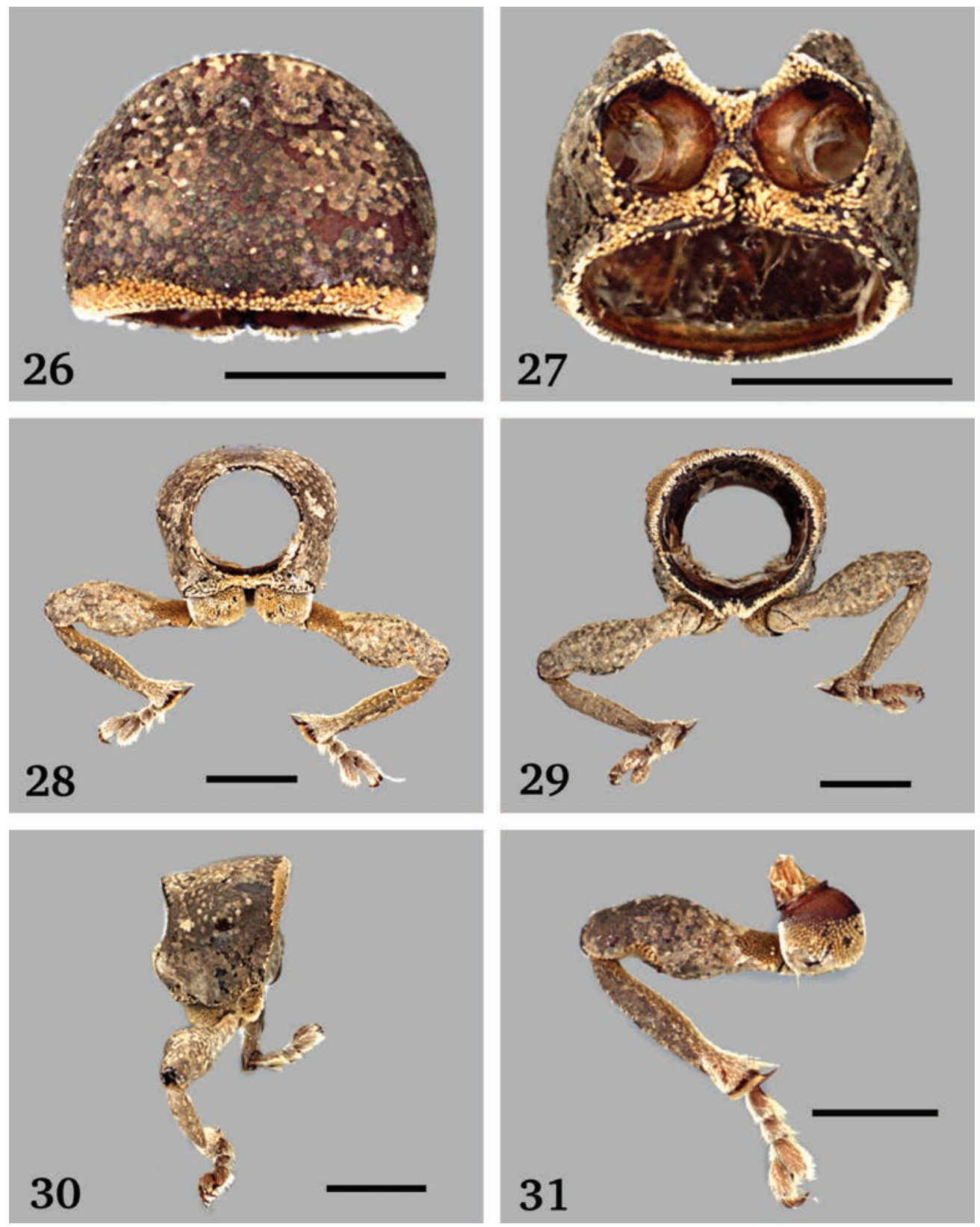

Figuras 26-31. Estructura del protórax de $N$. eichhorniae. (26 y 27) Protórax en vista dorsal y ventral. (28 y 29) Protórax en vista anterior y posterior con el primer par de patas. (30) Vista lateral de protórax. (31) Vista posterior de la pata protorácica derecha. Escala: $1 \mathrm{~mm}$. 
(1993) y Marvaldi \& Lanteri (2005) mencionan que las patas protorácicas proveen de numerosos caracteres para diferenciar especies dentro de la familia Curculionoidea. De acuerdo con Marvaldi \& Lanteri (2005), las coxas están separadas, el trocánter está reducido y de forma subtriangular; el resto de las características son similares a lo reportado por Warner en 1970 y O’Brien en 1976.

Pterotórax. La ornamentación del área ventral pterotorácica y abdominal es principalmente de escamas grandes y redondas, excepto alrededor de las fosas coxales donde las escamas son más pequeñas como ya se describió en el protórax. La primera placa esclerosada del pterotórax es el esternón mesotorácico de bordes anteriores lisos, ornamentado con escamas pequeñas y claras, y delimitado a los lados por dos surcos en diagonal. El borde posterior del esternón mesotorácico se curva para formar la parte anterior de las fosas coxales medias, y al centro se prolonga hacia atrás en un esclerito truncado que separa a las dos coxas (Fig. 33). La pleura mesotorácica está reducida a un esclerito triangular, casi oculto entre el protórax y los élitros (Figura 34). La principal protección del complejo pterotorácico y abdominal está formada por los dos élitros que forman sobre esta mitad del cuerpo una coraza convexa, cubierta en su totalidad por escamas de tonos variados que le dan al insecto su apariencia característica. Las escamas son en general más claras en la mitad anterior de los élitros, y el margen anterior de éstos tiene escamas pequeñas y amarillas. Los élitros están marcados por ocho franjas longitudinales, delimitadas por siete surcos que inician desde el borde anterior y convergen en el posterior. Las características de los élitros coinciden con lo reportado por Warner (1970), DeLoach (1975), O’Brien (1976), Center (1988) y Julien et al. (1999). Presentan marcas elitrales en su parte anterior con una longitud desigual, la coloración de las escamas no tiene la forma de V sobre los élitros como en $N$. bruchi. Cada élitro tiene en la mitad anterior de su franja mesal, donde se unen ambos, una barra longitudinal de cutícula desnuda y brillante que juntas forman una marca de dos líneas verticales paralelas propias de esta especie (Figs. 18 y 35). Las patas mesotorácicas se diferencian de lo ya descrito para las patas anteriores solamente en que la parte más ancha del fémur tiene un diámetro ligeramente menor, las tibias son un poco más cortas, y el espolón de la tibia es notoriamente más pequeño que el de la tibia protorácica (Fig. 38).

El esternón metatorácico es la placa ventral más extensa de todo el cuerpo; tiene bordes anteriores y posteriores ligeramente curvos y lleva en la línea ventral longitudinal media un canal que recorre la mitad posterior de la placa y en su extremo anterior se bifurca en dos brazos cortos para formar una figura en "T". En el borde anterior del esternón están las dos fosas coxales metatorácicas, separadas por una prolongación cuadrangular del basisternito. A los lados, esta placa esternal crece hacia arriba para terminar junto a la barra esclerosada del episternón pleural (Fig. 32). Las pleuras metatorácicas son relativamente simples; tienen un esclerito muy fuerte, alargado y de posición horizontal que corresponde a la parte expuesta del episternón, el 

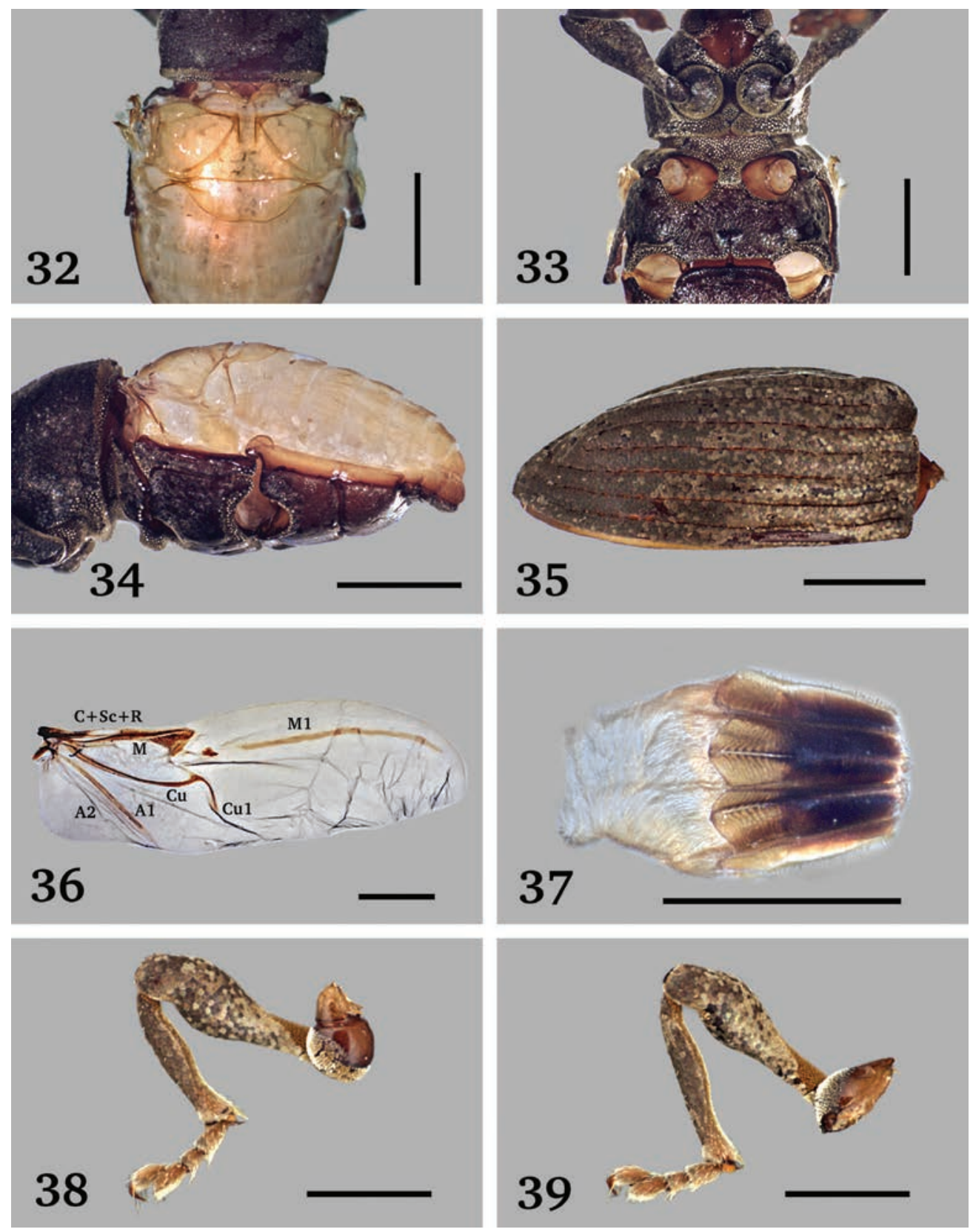

Figuras 32-39. Estructura del pterotórax de N. eichhorniae. (32-34) Pterotórax en vista dorsal, ventral y lateral. (35), élitro derecho. (36) Área dorsal del ala metatorácica. (37) Vista lateral del proventrículo. (38 y 39) Patas derechas de mesotórax y metatórax. Escala: 1 mm. 
cual tiene también una estrecha zona superior debajo de los élitros, de cutícula débil y clara, delimitada por el surco pleural inclinado y oscuro que sube hasta la articulación de los élitros. El epímeron es una estrecha franja de cutícula únicamente delimitada adelante por el surco pleural, que se desvanece en una amplia área posterior de cutícula transparente, casi membranosa. La parte posterior de esta pleura está cerrada por un gran esclerito ovalado, de cutícula clara y bordes débiles, que corresponde a la extensión del brazo postalar (Fig. 34). El área tergal metatorácica, de cutícula transparente y coloración débil, tiene una franja anterior o prescutum, dividida en una parte media y dos laterales convexas y una central triangular. En el vértice anterior del triángulo escutal hay dos líneas cortas, rectas y paralelas que corresponden a surcos parapsidales medios. Atrás del scutum metatorácico está el scutellum, de cutícula muy débil que forma un esclerito curvo, con una amplia zona membranosa entre él y el scutum. Los extremos laterales del scutellum terminan en una barra sinuosa (posnoto) que se curva hacia abajo hasta llegar al brazo postalar (Fig. 32). Las alas metatorácicas tienen en el borde costal de su base una pequeña vena $\mathrm{C}+\mathrm{Sc}+\mathrm{R}$ que en esta especie muestra su mitad distal en forma de una celda ovalada de cutícula clara. En el extremo distal de la vena M hay un esclerito triangular oscuro y ornamentado. La M1 está bien marcada como una franja de cutícula coloreada, pero la M2, a diferencia de otros curculionidos, es aquí apenas una inflexión longitudinal de la membrana alar. El extremo terminal de la vena $\mathrm{Cu}$ se une por un puente cuticular muy delgado al esclerito de la M. La Cu1, esclerosada en su unión con la Cu, no llega al borde del ala. La vena A1 está esclerosada y alcanza el borde posterior del ala; la A2 es sólo una línea sin esclerosamiento (Fig. 36). En las patas metatorácicas la coxa es alargada, de posición transversal cubierta por escamas pequeñas y blancas solamente en su lado externo; el resto del segmento es de cutícula lisa y brillante. Las otras características de las patas metatorácicas, incluyendo sus dimensiones, son iguales a las descritas para las patas medias (Fig. 39).

En la cavidad interna del pterotórax se encuentra el proventrículo, formado por seis placas dobles que se unen longitudinalmente para formar una estructura tubular más ancha en su parte anterior donde la cutícula es también más clara. De las láminas dobles que forman a cada placa proventricular crecen hacia la luz del tubo, en la mitad anterior del órgano, espinas ordenadas en líneas diagonales; en la mitad posterior de las placas, en cambio, los crecimientos internos son densos y desordenados, lo que da a la estructura una apariencia oscura. El borde anterior del proventrículo se continúa hacía adelante con la cutícula membranosa del buche, cubierta en su interior por espinas claras y densas (Fig. 37).

De acuerdo con Marvaldi (2005), algunas familias y tribus de Curculionidae pueden ser fácilmente reconocidas por el mesoepimerón ascendente (por ejemplo en Baridinae, Conoderinae, y Curculioninae de la tribu Ceutorhynchini). El mismo autor menciona que otro esclerito utilizado es el metaepimeron, el cual puede estar cubierto 
o no; de estarlo, su vestidura es brillante, delgada y más escasa que el metaepisternón. Para el caso de las alas, a diferencia de la especie Conotrachelus perseae (Barber), la M2 y Cu se desvanecen conforme se dirigen hacia el borde inferior del ala, de acuerdo con lo reportado por Domínguez (2006). La misma autora menciona que el proventrículo es una estructura de utilidad para el reconocimiento de géneros en Curculionidae.

Abdomen. En el área esternal del abdomen hay cinco placas ventrales esclerosadas, la primera de las cuales representa a los esternones I a III, como corresponde al abdomen sinfiogastro de los curculiónidos. Esta primera placa esternal tiene un borde anterior curvo y muy esclerosado; a los lados, el borde anterior constituye a la mitad posterior de las fosas coxales metatorácicas. El margen posterior de la mencionada placa es casi recto excepto por una pequeña escotadura situada en el punto medio. La placa esternal IV es tan ancha como la I-III; su borde anterior es notoriamente mayor que el posterior debido a que los márgenes laterales convergen hacía atrás. Los esternones V y VI son dos estrechas placas cuticulares paralelas, situadas en el fondo de una concavidad caudal, atrás de la marcada curvatura convexa de los esternones anteriores (Figs. 19, 40 y 41). El esternón VII es la última placa ventral visible y forma ventralmente la parte inferior de la terminalia abdominal. Los tergos abdominales, siempre ocultos por los élitros, tienen una cutícula tan delgada que a través de ella se pueden observar los órganos internos (Fig. 43). Hay siete tergos abdominales visibles que disminuyen en anchura hacia atrás; los dos últimos tienen cutícula más fuerte debido a que pueden quedar expuestos durante la extensión de la terminalia (Fig. 42).

Genitalia. La morfología externa del abdomen no muestra diferencias significativas entre ambos sexos. El esternito abdominal VIII está muy modificado y se sitúa en el fondo de la cámara genital; en la hembra tiene un apodema esclerosado de extremo anterior ligeramente curvo y dos brazos posteriores amplios y aplanados con bordes internos aserrados y extremos que terminan en puntas curvas dirigidas hacia adentro en las que hay varios sénsulos (Fig. 45). Los brazos posteriores del esternito VIII del macho, en cambio, están esclerosados uniformemente en toda su longitud, al igual que el apodema central, pero tienen además crecimientos aplanados laterales de cutícula delgada y rugosa (Fig. 47). En el interior del abdomen femenino, a la altura del segmento V, se encuentra la espermateca, debajo de la cutícula tergal. El bulbo de la espermateca está dirigido hacia atrás y muestra ornamentaciones de estrías transversales internas que llegan hasta el tubo esclerosado curvo con el que la espermateca se comunica con un esclerosamiento abultado anterior en el cual desemboca el tubo casi recto y esclerosado que recibe al conducto espermático procedente de la cámara genital femenina (Figs. 43 y 44). El complejo genital masculino está compuesto por un edeago de márgenes laterales casi paralelos y esclerosados que se unen en un extremo posterior en forma de "U" en la cual se encuentran ordenados radialmente un 

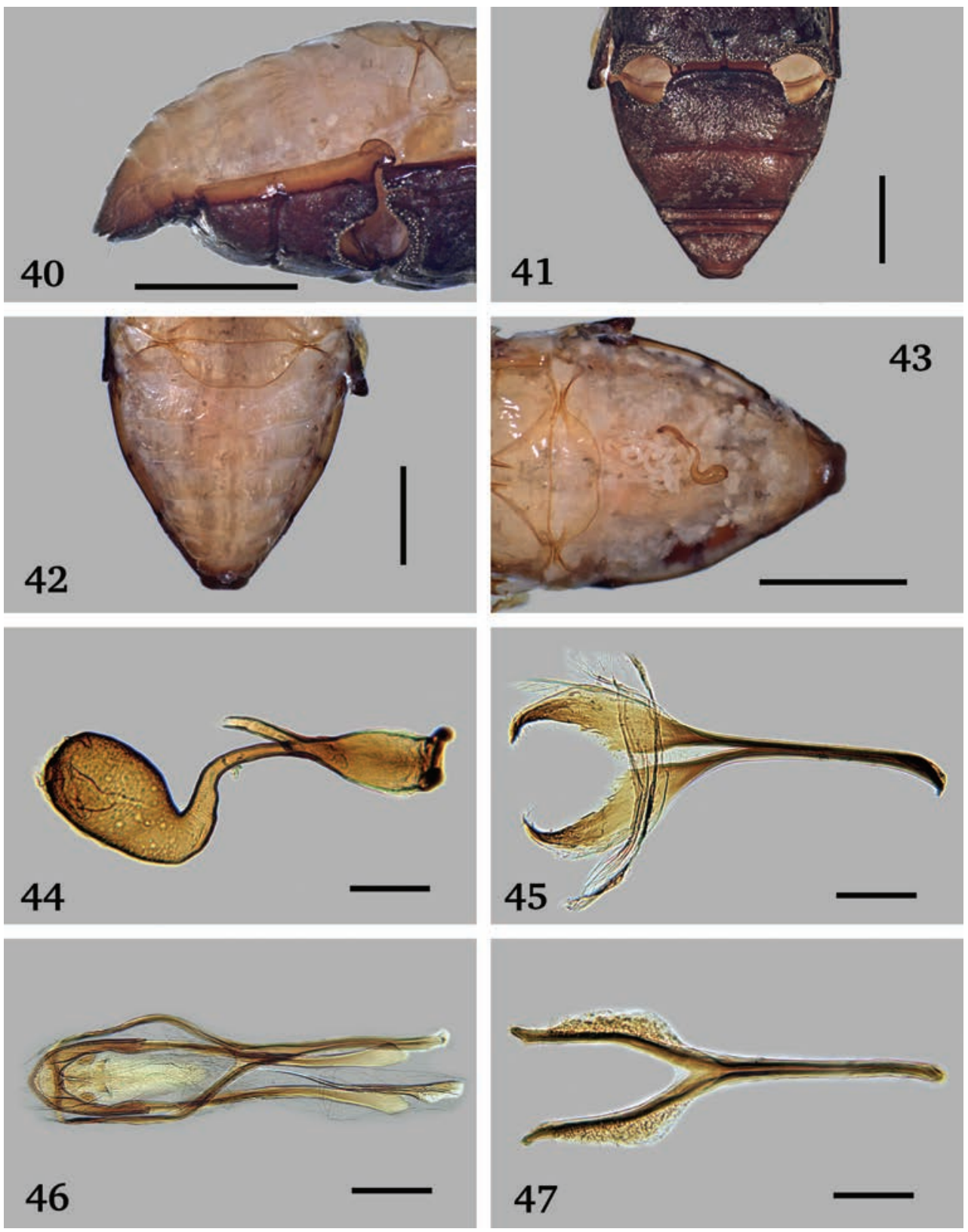

Figuras 40-47. Anatomía del abdomen y órganos genitales de $N$. eichhorniae. (40-42) Vista lateral ventral y dorsal del abdomen de la hembra. (43) Abdomen en vista dorsal sin cutícula. Escala 1mm. (44) Espermateca. (45) Octavo esternito abdominal de la hembra. (46) Vista dorsal del edeago. (47) Octavo esternito abdominal del macho. Vistas 6.3X. Escala $200 \mu \mathrm{m}$. 
gran número de órganos sensoriales. El resto de la cutícula del edeago es muy clara. Los esclerosamientos laterales del órgano se prolongan hacía adelante como dos apodemas edeagales con extremos anchos, aplanados y truncados. La cutícula anterior membranosa del cuerpo central del edeago envuelve a un endofalo tubular que lleva a una barra esclerosada de extremo anterior ancho y aplanado y extremo posterior fino y estrecho. El tegmen tiene un apodema un poco más largo que los apodemas edeagales y dos brazos laterales que rodean al edeago por los lados y se unen en sus extremos posteriores mediante un puente dorsal que cierra al anillo del tegmen (Fig. 46). O’Brien en 1976 presentó una revisión taxonómica del género Neochetina, en donde menciona que las porciones esclerosadas del endofalo son excelentes para separar a las especies. Cuatro especies presentan un flagellum, que en N. eichhorniae es más corto que el phallus, incluyendo apodemas; en affinis tiene solamente un par anterior de dientes curvos y en neoaffinis tiene un tubo medio alargado en forma de cono. También menciona que el esclerosamiento de espermateca y glándulas de la misma son diferentes, lo mismo para el octavo esternito.

La forma y proporción de la espermateca y glándulas de la espermateca son constantes. Hay pequeñas diferencias en el engrosamiento del ápice de diversos affinis y algunos son bífidos en el ápice.

\section{CONCLUSIONES}

Este estudio morfológico fortalece el conocimiento de los diferentes estados de desarrollo de Neochetina eichhorniae y puede ser de utilidad en el reconocimiento de la especie.

Agradecimientos. Al Dr. Alejandro Pérez Panduro por el pie de cría de N. eichhorniae, y al Dr. Jesús Romero Nápoles por la corroboración de la especie.

\section{LITERATURA CITADA}

Bennet, F. D. 1984. Biological control of aquatic weeds. pp. 14-40. In: Proceedings International Conference of Waterhyacinth. G. Thyagarajan, ed. UNEP Resources and Procces. Series 7. Nairobi, Kenya.

Castañeda, V. A., Valdez, C. J., Equihua, M. A., González, H. H., Romero N. J., Solís, A. J. F., \& Ramírez, A. S. 2007. Genitalia de tres especies de Hellipus Germar (Coleoptera: Curculionidae) que dañan frutos de aguacate (Persea americana Mill) en México y Costa Rica. Systematics, Morphology and Phyisiology. Neotopical Entomology, 36: 914-918.

Center, T. D., Dray, F. A. \& Vandiver, V. V. Jr. 1988. Biological control with insects: The Waterhyacinth Weevils. University of Florida. Cooperative Extension Service. Institute of Food and Agricultural Sciences. Fact Sheet AGR 88.

Center, T. D., Hill, M. P., Cordo, H. \& Julien, M. H. 2002. Water Hyacinth, In: Van Driesch, R. Biological control of invasive Plants in the Eastern United States, USDA Forest Service Publication FHTET-2002-04. 413p. 
Clark, W. E. 1993. The weevil genus Neomastix Dietz (Coleoptera: Curculionidae, Anthonomini). Coleopterists Bulletin, 7: 1-9.

Deloach, C. J. 1975. Identification and biological notes on the species of Neochetina (Coleoptera: Curculionidae: Bagoini) that attack Pontederiaceae in Argentina. Coleopterists Bulletin 9: 257-265.

Deloach, C. J. \& Cordo, H. A. 1976. Ecological Studies of Neochetina bruchi and N. eichhorniae on Waterhyacinth in Argentina. Journal of Aquatic plant Manegment, 14: 53-59.

Domínguez, J. V. 2006. Morfología del barrenador pequeño de la semilla Conotrachelus perseae (Barber) (Coleoptera: Curculionidae). Tesis de maestría. Colegio de Postgraduados Campus Montecillo. 56 pp.

Gaiger, F. \& Vanin, S. A. 2008. On utility of female genitalia in the sistematics of Curculionidae: examples from Entimini and Hylobiina (Coleoptera: Curculionidae). Annales de la Sociéte Entomologique de France, 44: 47-57.

Fernández, S. \& Cordero, J. 2007. Biología de la broca del café Hypothenemus hampei (Ferrari) (Coleoptera: Curculionidae: Scolytinae) en condiciones de laboratorio. Bioagro, 19(001): 35-40pp.

González-Hernández, A. \& López-Arrollo, J. I. 2007. Importancia de la sistemática en control biológico, pp. 36-47. In: L.A. Rodríguez del Bosque y H C Arredondo-Bernal (Eds.). Teoría y Aplicación del control biológico. Sociedad Mexicana de Control Biológico, México. 303 pp.

Gosik, R. 2009 Description of the larva and pupa of Tapeinotus sellatus (Fabricius) with comments on its biology (Coleoptera: Curculionidae). Wroclaw, 20: 137-147.

Julien, M. H., Griffiths, M. W. \& Wright, A. D. 1999. Biological Control of Waterhyacinth. The weevils Neochetina bruchi and $N$. eichhorniae: biologies, host ranges, and rearing, realizing and monitoring techniques for biological control of Eichhornia crassipes. ACIAR Monograph No. 60, $87 \mathrm{pp}$.

Martínez, J. M. 2005. Manual para la cría masiva de Neochetina spp. utilizado en el control biológico de lirio acuático. IMTA. México. 45pp.

Martinez, J. M., Gutierrez, E. L., Huerto D. R. \& Ruiz, F. E. 2001. Importation, Rearing, Release and Establishment of Neochetina bruchi (Coleoptera Curculionidae) for the Biological Control of Waterhyacinth in México. Journal of Aquatic Plant Management, 39: 140-143.

Marvaldi, A. E. 1997. Higher Level Phylogeny of Curculionidae (Coleoptera: Curculionoidea) based mainly on Larval Characters, with Special Reference to Broad-Nosed Weevils. Cladistics, 13: 285312.

Marvaldi, A. E. 2003. Key to Larvae of the South American Subfamilies of Weevils (Coleoptera, Curculionoidea). Rev. Chil. Hist. Ñata. Instituto Argentino de Investigaciones de las Zonas Áridas (IADIZA), 76: 603-612

Marvaldi, E. A. \& Lanteri, A. A. 2005. Key to higher taxa of South American weevils based on adult characters (Coleoptera, Curculionoidea). Revista Chilena de Historia Natural v.78 (1)

May, B. M. \& Sands, D. P. A. 1986. Descriptions of larvae and Biology of Cyrtobagous (Coleoptera: Curculionidae): Agents for Biological Control of Salvinia. Proceedings of the Entomological Society of Washington, 88: 303-312.

Oberholzer, H. 2001. The Water hyacinth weevils (Neochetina eichhorniae and Neochetina bruchi) A natural enemy of Water hyacinth (Eichhornia crassipes) in South Africa. Agricultural Research Council, PPRI. Weeds Research Division.

O'Brien, C. W. 1976. A taxonomic revision of the new world subaquatic genus Neochetina. Annals of the Entomological Society of America 69: 165-174.

Quiroz, R. M., Valdez, C. J., Vera, G. J. \& Castillo M. A. 2000. Identificación de los instares larvales de Zabrotes subfasciatus (BOH) (Coleoptera:Bruchidae) mediante las dimensiones de su cápsula cefálicas. Agrociencia 34(001): 83-90. 
Vallejo, F. M., Morón, A. \& Orduz, S. 2007. Biología de Phylophaga obsoleta Blanchard (Coleoptera: Melolontidae), especie rizófaga del complejo "Chisa” de colombia. Boletin científico-Centro de Museos- Museo de Historia Natural, 11: 188-204.

Warner, R. E. 1970. Neochetina eichhorniae, a new species of weevil from waterhyacinth, and biological notes on it and N. bruchi (Coleoptera: Curculionidae: Bagoini). Proceedings of the Entomological Society of Washington, 72: 487-496.

Wilcox, D. B., Dove, D., McDavid \& D. Greer. 2002. UTHSCSA Image Tool for Windows version 3.0. The University of Texas Health Science Center in San Antonio. U.S.A. 